\title{
Analysis and Reduction of the Sloshing Phenomena Due To Sudden Movement of Spray Mixture Tanker
}

\author{
G. B. Micheli ${ }^{1 \dagger}$, M. L. F. Fogal ${ }^{1}$, V. L. Scalon ${ }^{1}$, A. Padilha ${ }^{1}$ and K. A. R. Ismail ${ }^{2}$ \\ ${ }^{1}$ Department of Mechanical Engineering - FE/UNESP, Bauru, Sao Paulo, Brazil \\ ${ }^{2}$ Faculty of Mechanical Engineering - UNICAMP, Campinas, Sao Paulo, Brazil \\ †Corresponding Author Email: gustavobm.micheli@gmail.com
}

(Received April 5, 2021; accepted October 11, 2021)

\begin{abstract}
The sloshing phenomenon occurs in partially filled tankers due to sudden movement can affect the tank structure integrity and impair the dynamic stability of the tanker. The effects of sloshing phenomena in a spray mixture tank due to acceleration or deceleration of the agricultural vehicle is investigated under three filling levels of $25 \%, 50 \%$, and $75 \%$. The pressure time distributions on the tank wall were evaluated by using a multiphase transient model (water and air as an ideal gas) and a free surface flow in a homogeneous model. It was possible to verify the wave behavior of sloshing. The condition of $75 \%$ tank filling volume generated the highest pressure on the tank wall. The effectiveness of two types of vertical baffles in suppressing pressure was numerically investigated. Shear stress on the tank bottom wall under these proposed arrangements was analyzed by steady-state models and mechanical agitation, considering a filled tank. The proposed solution based on two partial vertical baffles and a central gap was the most effective. It promotes the higher reduction of wall impact pressure and other sloshing instabilities and maintains similar results of mixture agitation of the tank without baffles.
\end{abstract}

Keywords: Sloshing; Impact pressure; CFD analysis; Spray tank; Tank with baffles

\section{NOMENCLATURE}

$\begin{array}{ll}f & \text { variable function value } \\ C_{\varepsilon} & \text { k- } \varepsilon \text { model constant } \\ g & \text { gravity acceleration } \\ k & \text { turbulent kinetic energy } \\ M_{\alpha} & \text { sum of interface forces } \\ P & \text { total pressure } \\ p & \text { order of numerical convergence } \\ P_{k} & \text { production rate of turbulent } \\ & \text { kinetic energy } \\ P_{k b}, & \text { influence of body forces on turbulence } \\ P_{\varepsilon b} & \text { influence of body forces on turbulence } \\ r & \text { phase volumetric fraction }\end{array}$

\section{INTRODUCTION}

The sloshing phenomenon occurs due to the movement of the fluid having a free surface in a bounded container. A partially filled tank may experience sloshing under various circumstances, including resonance phenomenon, where the free surface can deform and increases in amplitude along the sidewalls. Hence, the design and analysis of road and off-road tankers requires consideration of dynamic slosh loads to reduce the adverse effect on directional dynamic performance and stability of

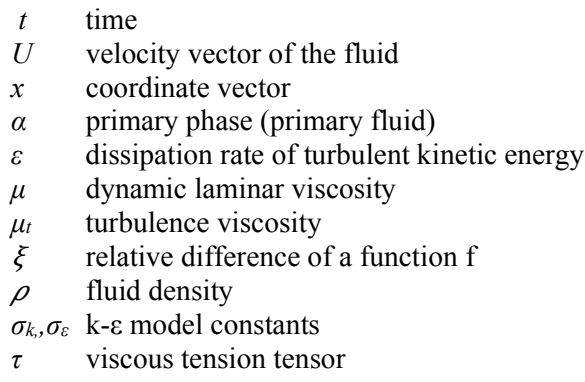

vehicle tanks (Kolaei et al. 2017). For agricultural machines, this effect is encountered both in the tanks of spray mixture for agricultural implements coupled to tractors and to self-propelled machines which have fuel tanks. Several devices and design solutions are adopted to minimize the sloshing effects in tanks. One of these solutions is the use of bulkheads that divide the tank into smaller compartments and shift away from the natural frequency of sloshing from the frequency range of critical excitations. However, this solution increases both the weight and cost. 
In order to reduce costs with prototypes of tanks, numerical simulation of sloshing and the phenomena involved in the agitation are carried by computational fluid dynamics (CFD) code, which uses the finite volume technique as a method of discretization of the fluid domains. Hosain et al. (2018) investigated numerically the effects of liquid sloshing in carrier ship fuel tanks, to understand the flow structures and validate the downscaling approach based on the similarity scale laws. The main advantage of the CFD technique is its flexibility to change process parameters, flow regimes, location of wave break geometries, location of agitators, tank geometry and do not necessarily use a full-scale model.

Numerical simulation techniques based on solving potential equation have been widely applied for modeling liquid sloshing in baffled tanks, and the results of pertinent studies will be discussed briefly in this work. Myrillas et al. (2017) studied sloshing in a Heavy Liquid Metal (HLM) nuclear reactor under seismic excitation and noted induction of additional forces on the structures. A study on a simplified cylindrical model applying sinusoidal excitation was carried out using CFD. The results are compared with dedicated experiments, providing good qualitative validation of the numerical tools. Park et al. (2019) presented a simple analytical method, namely, modified linear theory, for predicting the sloshing motions of a rectangular pool under some excitation frequencies. Splashed water on the wall or around the wall was predicted for high and low excitation frequencies. The sloshing height indicated via CFD analysis resulted much higher than that via the modified linear theory. These differences in results could also be due to neglected parameters, such as the viscoelasticity and surface tension, which are fluid properties and nonlinear.

This could also be observed in an analytical model of a partly filled tank of arbitrary cross-section, developed for predicting transient lateral slosh force and overturning moment using linear slosh theory (Kolaei et al. 2014). The forces and moments caused by fluid slosh under steering or braking maneuvers have been associated with reduced stability limits and poor directional performance of partly filled tank trucks. According to this work, many studies of dynamic sloshing waves in partly filled containers using CFD codes have invariably concluded that peak slosh forces and moments are substantially greater than those predicted from a quasi-static model. Nicolsen et al. (2017) also investigated the dynamic behavior of the tanker truck model in three different motion scenarios numerically. In the first one, the truck decelerates under straight-line motion, exerting sloshing longitudinal forces on the tank. In the second scenario, the truck performs a lane change, alternating sloshing lateral forces on either side of the tank. In addition, the third one, the truck is assumed to do a wide curve, with a continuous sloshing lateral force exerted on one side of the tank. The results demonstrated that depending on the scenario, the sloshing phenomenon could increase the contact forces on some wheels while decreasing contact forces on other wheels, and this can lead to vehicle instability by raising the possibility of wheel lift.

Iranmanesh and Passandideh-Fard (2017) studied numerically the feasibility of using a submerged cylinder as a mitigation device to absorb the kinetic energy of water sloshing in a container undergoing a constant and variable excitation. Celis et al. (2017) analyzed the behavior of confined water and airflows in a partially filled tank. The effect of anti-slosh baffles on free liquid oscillations depends on the baffle installation position that has distinct effects on the sloshing frequencies and the associated hydrodynamic pressure fields. For this, the phenomenon was investigated following the methodology based on the conservation of the volumetric fraction to represent the free surface. Wang et al. (2017) studied the effect of various baffles on liquid oscillations in partially filled rigid toroidal tanks in order to avoid failure of structure system due to the undesirable dynamic behaviors. Qin et al. (2019) presented a numerical study on the structural response of horizontal and vertical baffles of different configurations in a sloshing tank considering hydroelasticity to guarantee structural safety. Bellezi et al. (2019) investigated a comprehensive study of the sloshing within boxshaped tanks equipped with perforated bulkheads. Numerical simulations using proposed swash bulkhead geometries confirmed the effectiveness of the relation of optimized open-area ratio as a function of the filling ratio. Zhang et al. (2019) also investigated an anti-sloshing device using floating foams in a rectangular liquid tank. The results showed that even a single layer of floating foams could reduce the sloshing forces due to energy dissipation, and the amplitude of dynamic pressure in the tank was also found to decrease as the number of foam layers increases.

Micheli et al. (2015) conclude that in the case of spray mixture tanks, the efficiency of the homogenization of the mixture inside the tank has a great impact on the quality of the application and the treatment of a crop and can be hampered by the introduction of anti-sloshing devices. On the other hand, Pukkella et al. (2019) and Gu et al. (2019) studied experimentally and numerically mixing in stirred tanks for the process industry. In this type of tank, the effectiveness of mixing is typically improved through baffles and fractal impellers. The results showed under different tank conditions that interface baffled system provided much better mixing characteristics.

Xue et al. (2017) conducted a detailed experimental investigation to determine sloshing pressure effects on the baffle and the tank wall. They used different vertical baffle configurations over various frequencies, including immersed bottom-mounted vertical baffles, vertical baffles flushing with a free surface, surface-piercing bottom-mounted vertical baffles, and perforated vertical baffles. The experimental results showed that changing flow fields and altering natural frequency can effectively suppress the impact pressure on the walls of the tank. 
The literature review reveals the important effects of the sloshing phenomenon that occurs in partially filled tankers in movement and how these effects can impact the tank structure integrity and impair the dynamic performance of the tanker when subject to sudden acceleration or abrupt deceleration. To alleviate these effects, two possible arrangements are proposed for investigation and analysis. The first arrangement refers to installing in the interior of the tank a separating baffle with a longitudinal cut from the top to half height of the fluid tank. The second proposed arrangement refers to installing a baffle covering the top to half of the tank height with five circular holes in the upper part of the baffle. The actual arrangement (used as a reference for comparison) refers to the tank without any internal baffles. The three configurations are simulated by CFD, and their hydrodynamic characteristics, such as pressure distribution and free surface movements, are presented and discussed.

The main contribution of the present investigation is proposing some arrangement that at the same time reduces the undesirable effects of sloshing on the dynamic stability and mechanical integrity of tankers and maintains the homogeneity of the mixed liquid product inside. A detailed analysis via CFD indicated that the most viable arrangement is the cut baffle to half the tank height. It allows proper pressure distribution on the tank walls and introducing the anti-sloshing device does not hamper the agitation.

\section{NUMERICAL SETUPS}

\subsection{Description of the sloshing problem}

In this work, the effect of sloshing on an agricultural sprayer tank of 4500 liters capacity, Fig. 1, for nonperennial crops is evaluated. A mechanical agitator is positioned near the bottom of the back wall to promote agitation inside the tank. For analysis of sloshing effects in transient models, the agitator influence is negligible. However, when evaluating some proposed simulation models to decrease these effects, the influence of devices inside the tank on mixture agitation is considered as a solution requirement.

The liquid sloshing in tanks is a very complex nonlinear physical phenomenon, and the dynamic impact pressure distributions on the tank walls are considered critical factors in the design of these tanks. Figure 2 shows the position of the pressure capture points on the tank wall to compare sloshing effects.

The evaluation of the effects of sloshing due to the braking deceleration of the vehicle is carried out in three levels of tank filling $(25 \%, 50 \%$, and $75 \%)$ and without mechanical agitation to define the most critical conditions for its structural dimensioning. Figure 3 shows the simplification of the acceleration versus time in the $z$-direction (positive horizontal direction from right to left) which is applied in the models. In the beginning, the sprayer accelerates in a straight line (in the z-direction) to achieve the maximum work speed allowed for soil condition, and later on, decelerating at the end of the field row. This scenario could occur if braking is suddenly applied

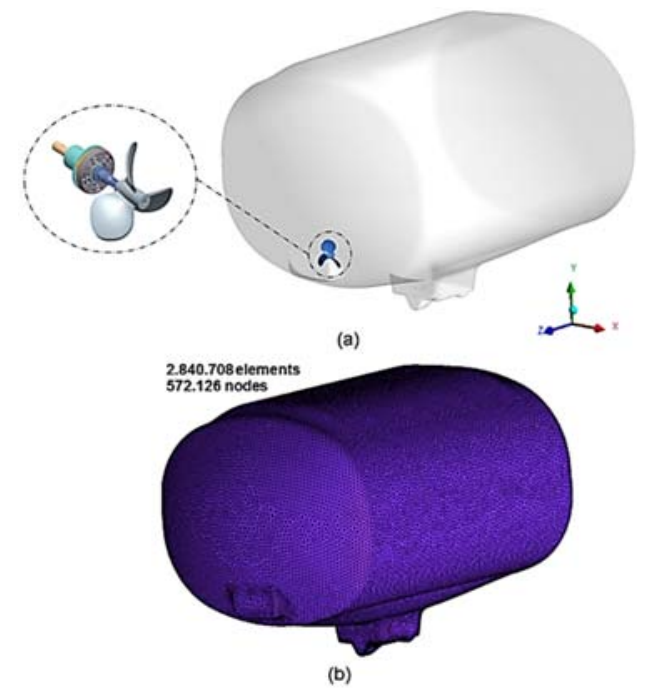

Fig. 1. Domain for sprayer tank of 4500 liters: (a) 3D models of tank and mechanical agitator, and (b) tank mesh.

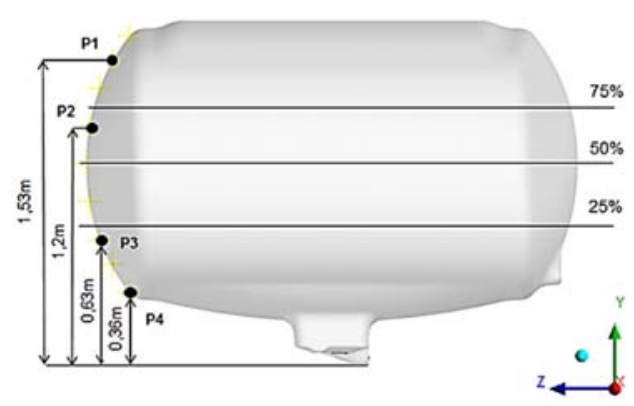

Fig. 2. Positions of tank fill levels and pressure capture points.

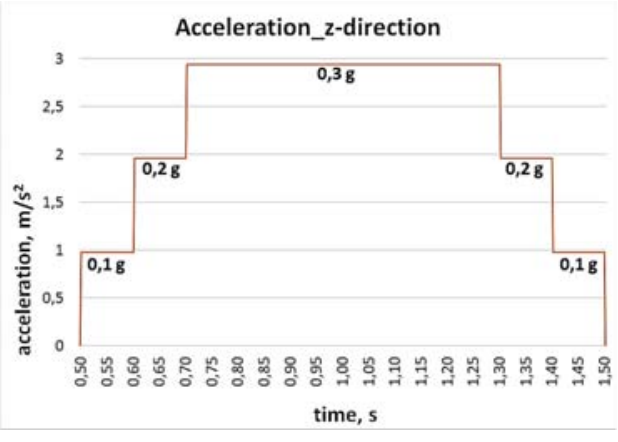

Fig. 3. Acceleration and deceleration in the $\mathrm{z}$ direction in the beginning of simulation period.

in an attempt to avoid a collision of the spraying boom or preparing the machine to make a maneuver to enter in another field row, e.g.

It is unclear what is more critical for dimensioning the tank walls, the filling height of the tank (larger spray mixture volume) or the air volume that allows more significant displacement of the spray mixture 
volume. Therefore, this is investigated to optimize the number of simulation models to check the arrangements for decreasing sloshing effects.

In the present work, two different arrangements to decrease the sloshing effects on the spray tank walls are presented in Fig. 4. In developing the concept of the proposed arrangements, the requirement to maintain a good agitation of the tank mixture without the need for additional agitator (mechanical or hydraulic) and achieve shear stress levels on the lower walls more than $0.3 \mathrm{~Pa}$ (Micheli et al. 2015) was carefully observed. The velocity variation between the different flow layers promotes regions of greater or lesser shear stress. Higher values of shear stress on the wall mean greater velocity gradient in this region and, therefore, more substantial fluid movement than in regions with lowstress values. As a result, regions with low values of shear stress are subject to greater occurrence of residues deposition.

Arrangements 1 and 2 are based on the use of partial baffles in order not to impair the tank mixture agitation efficiency. The first arrangement uses two partial vertical baffles and a central gap, while the second arrangement uses one partial vertical baffle with five holes to allow the flow through the baffle.

Figure 5 shows the mesh distribution for the two proposed arrangements. The mesh refinement was chosen based on the numerical validation of the mesh dependence results, and it is presented later in Section 4. Both arrangements have unstructured meshes, with 3,097,598 elements and 656,222 nodes, and 3,246,812 elements and 701,591 nodes, for arrangement 1 and 2 , respectively.

\subsection{Numerical Methods}

Numerical simulations were performed using the commercial CFD code, ANSYS CFX 18.1, with non-structured tetrahedral meshes generated by software ICEM CFD 18.1. All simulations were carried out in 3D, performed in parallel on an Intel (R) Core(TM) i7-6700HQ CPU @ $2.6 \mathrm{GHz}$ processors with 16 GB RAM.

Simulation transient models were used to predict the behavior of sloshing waves without mechanical agitation. In pre-processing, the definition of the parameters of the transient models is briefly described as follows: homogeneous multiphase model (free surface model), fluids defined as water (for spray mixture) and air (ideal gas), with reference temperature equal to $25^{\circ} \mathrm{C}$; transient analysis type and turbulent; isothermal flow; surface tension coefficient equal to $0.072 \mathrm{~N} / \mathrm{m}$; no-slip walls. The total simulation time was 6 seconds for all transient cases.

On the other hand, to verify if the agitation requirement is achieved by the proposed arrangements to reduce the sloshing effects, steadystate models with mechanical agitation were used. In mesh generation, to reduce the number of elements and nodes, and consequently, the computational effort, two different domains were created: one stationary domain to represent the bulk of the tank

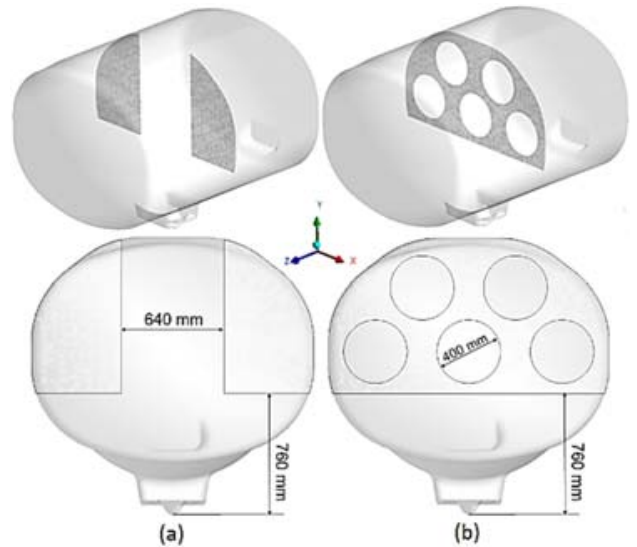

Fig. 4. Proposals for decreasing the sloshing effects: (a) arrangement 1; (b) arrangement 2.
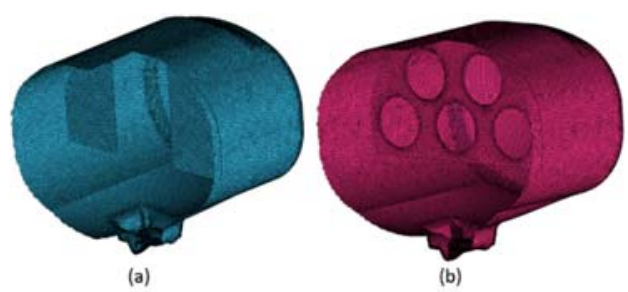

Fig. 5. Mesh: (a) arrangement 1, and (b) arrangement 2 .

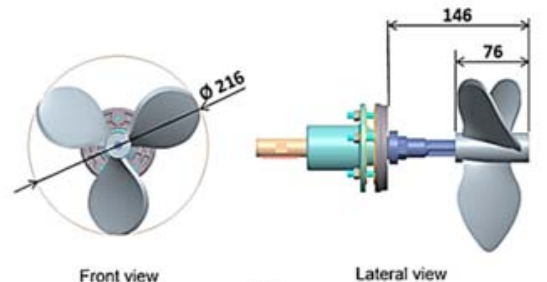

(a)

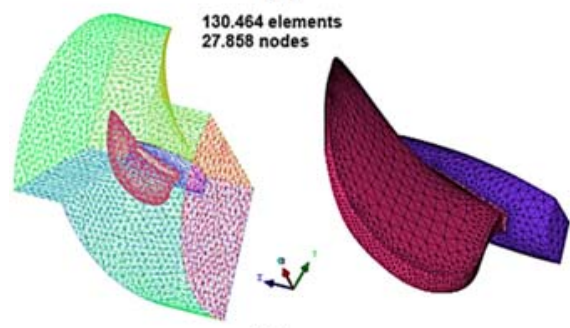

(b)

Fig. 6. Mechanical agitator: (a) views of 3D model, and (b) mesh of rotating domain.

volume, and one rotating domain to represent the mechanical agitator. Figure 6 shows details of the agitator 3D model and mesh. The steady-state models are described as follows: fluid defined as water with reference temperature equal to $25^{\circ} \mathrm{C}$; fully filled tank; steady-state analysis type and turbulent; isothermal flow; no-slip walls; rotation of mechanical agitator equal to $540 \mathrm{rpm}$. 
The turbulent mean field was obtained for all the simulation models using the Reynolds Averaged Navier Stokes (RANS), while the turbulence model used to close the set of equations was the k- $\varepsilon$ model of two equations. The adopted numerical convergence is when the sum of normalized residuals was lower than $1 \mathrm{E}-04$ for all variables for each time step.

\section{MATHEMATiCAL MODEL}

\subsection{Transport Equations}

The mathematical model used in this computational simulation is based on the mass conservation equation and the Navier-Stokes transport equations, which describe the phenomena of movement, energy and mass transport, described by Fogal et al. (2021).

The analytical solution of these partial differential equations is performed through the finite volume technique, where the equations are discretized and the resulting algebraic equations are solved iteratively for each control volume. As a result, an approximation of the value of each variable assigned to specific points across the domain can be obtained.

Reynolds stress tensor acting on the fluid, present in the momentum equation, can be calculated using a turbulence model, and arises as a result of the timeaveraging or spatial filtering procedure, and is used to mimic the momentum transport due to turbulence motion (Liu et al. 2017).

\subsection{Turbulence modeling}

Various turbulence models are applied in many numerical studies of sloshing or mixture agitation, with different prediction accuracy. It depends on turbulence levels and dissipation for breaking waves and how complex the geometries of anti-sloshing devices and tank walls are. The present work employs the standard $\mathrm{k}-\varepsilon$ model for turbulence closure in the RANS approach. Liu et al. (2020) adopted this turbulence model in a study of fluid sloshing in a fuel storage tank, and maximum relative errors between the numerical and experimental results were less than $5.0 \%$. Micheli et al. (2015) showed satisfactory simulation results of mixture agitation comparing with experimental ones using this turbulence model with low computation efforts. So, within the framework of this model, the transport equations for $\mathrm{k}$ and its dissipation rate $\varepsilon$ are:

$\frac{\partial}{\partial t}(\rho k)+\frac{\partial}{\partial x_{j}}\left(\rho U_{j} k\right)=\frac{\partial}{\partial x_{j}}\left[\left(\mu+\frac{\mu_{t}}{\sigma_{k}}\right) \frac{\partial k}{\partial x_{j}}\right]+$
$P_{k}-\rho \varepsilon+P_{k b}$

$\frac{\partial}{\partial t}(\rho \varepsilon)+\frac{\partial}{\partial x_{j}}\left(\rho U_{j} \varepsilon\right)=\frac{\partial}{\partial x_{j}}\left[\left(\mu+\frac{\mu_{t}}{\sigma_{\varepsilon}}\right) \frac{\partial \varepsilon}{\partial x_{j}}\right]+$ $\frac{\varepsilon}{k}\left(C_{\varepsilon 1} P_{k}-C_{\varepsilon 2} \rho \varepsilon+C_{\varepsilon 1} P_{\varepsilon b}\right)$

where, $\rho$ is the fluid specific mass; $t$ is time; $U_{j}$ is the mean flow velocity; $\mu_{t}$ is the eddy viscosity; $\mathrm{P}$ is the static pressure; $\mathrm{k}$ is the turbulent kinetic energy; $\varepsilon$ is the dissipation rate of turbulent kinetic energy; $\mathrm{P}_{\mathrm{kb}} \mathrm{e}$ $\mathrm{P}_{\varepsilon b}$ represent the body forces influence, $\mathrm{P}_{k}$ is the production of turbulent kinetic energy due to viscous forces. $\mathrm{C}_{\varepsilon 1}, \mathrm{C}_{\varepsilon 2}, \sigma_{\mathrm{k}}$ and $\sigma_{\varepsilon}$ are empirical constants with values $1.44 ; 1.92 ; 1.0$ and 1.3 , respectively. This RANS $k-\varepsilon$ model with the above coefficients was used in the liquid sloshing studies in e.g. Liu et al. (2016), Saghi and Lakzian (2017), and Liu et al. (2019; 2020).

\subsection{Free surface modeling}

Prediction of sloshing phenomena requires a simulation model that can examine the free surface of the liquid in a period. In this present system, the method used to solve incompressible Navier-Stokes equations with a free surface condition on the free boundary is the Homogeneous Multiphase Model (Eulerian-Eulerian model). Free surface flow refers to a multiphase flow situation where the phases are separated by a distinct resolvable interface. The volume fraction of the fluid in consideration (phase $\alpha$ ) is $r$, and 1-r is the volume fraction of the secondary fluid. The volume fraction values are 0 or 1 except near interface. The phases not mixed at microscopic scale and share the velocity field $\left(U_{i}=U_{j}\right)$, essentially, a single-phase momentum equation with mixture density and viscosity. The phase momentum equation and the sum over phases are given as Eq. (3) and (4) (Ansys CFX 2017):

$$
\begin{aligned}
& \frac{\partial}{\partial t}\left(r_{\alpha} \rho_{\alpha} U_{\alpha}^{i}\right)+\frac{\partial}{\partial x_{j}}\left(r_{\alpha} \rho_{\alpha} U_{\alpha}^{j} U_{\alpha}^{i}\right)=-r_{\alpha} \frac{\partial P}{\partial x_{i}}+ \\
& r_{\alpha} \rho_{\alpha} g_{i}-\frac{\partial}{\partial x_{j}}\left(r_{\alpha} \tau_{j i}\right)+M_{\alpha} \\
& \frac{\partial}{\partial t}\left(\rho U_{i}\right)+\frac{\partial}{\partial x_{j}}\left(\rho U_{j} U_{i}\right)=-\frac{\partial P}{\partial x_{i}}+\rho g_{i}-\frac{\partial \tau_{j i}}{\partial x_{j}} \\
& \text { where, } \quad \rho=\sum_{\alpha} r_{\alpha} \rho_{\alpha} \\
& \text { and, } \quad \tau_{j i}=\sum_{\alpha} r_{\alpha} \tau_{\alpha}^{j i}
\end{aligned}
$$

$\mathrm{r}_{\alpha}$ is the volume fraction for phase $\alpha$; $\mathrm{g}$ is gravity acceleration; $\tau_{\mathrm{ji}}$ is the Reynolds stress tensor; $\mathrm{M}_{\alpha}$ is the sum of interfacial forces (in this case, turbulent dispersion and momentum transfer associated with mass transfer).

\section{Results AND Discussions}

\subsection{Numerical uncertainty assessment}

It is known that parameters such as mesh refinement and time step size directly influence the computational accuracy, stability, and efficiency of a CFD simulation, and both mesh and time step dependence studies are necessary (Jiang et al. 2015; Lyu et al. 2017; Sufyan et al. 2017). Therefore, the transient model for the no baffles tank was analyzed as a reference for all other cases to ensure good quality solutions. Four unstructured meshes were generated to evaluate the mesh dependence of the model results, which are coarse $(2,272,566$ elements and 465,143 nodes), baseline $(2,840,708$ elements and 572,126 nodes), medium (3,578,074 elements and 703,982 nodes) and high refinement (4,419,448 elements and 767,509 nodes). Table 1 shows a summary of the mesh dependence results for transient models with no tank baffles. Note that $\xi$ is the relative difference in the solutions obtained at 
G. B. Micheli et al. / JAFM, Vol. 15, No. 2, pp. 399-413, 2022.

Table 1 Mesh dependence analysis for no baffles tank transient models

\begin{tabular}{|c|c|c|c|c|c|}
\hline Mesh & Description & $\begin{array}{c}\text { Number of } \\
\text { Elements (n) }\end{array}$ & $\begin{array}{c}\text { Minimum Element } \\
\text { Quality* }\end{array}$ & $\begin{array}{c}\text { Pressure } \\
\text { peaks at P4 (Pa) }\end{array}$ & $\begin{array}{c}\text { Relative } \\
\text { difference }(\xi)\end{array}$ \\
\hline 1 & Coarse & $2,272,566$ & 0.185 & no convergence & - \\
\hline 2 & Baseline & $2,840,708$ & 0.275 & 14,195 & $3.4 \%$ \\
\hline 3 & Medium & $3,578,074$ & 0.313 & 13,732 & $2.4 \%$ \\
\hline 4 & High & $4,508,373$ & 0.396 & 13,405 & $\mathrm{p}=1.51$ \\
\hline
\end{tabular}

Table 2 Time step dependence analysis for no baffles tank transient models

\begin{tabular}{|c|c|c|c|c|}
\hline $\begin{array}{c}\text { Time } \\
\text { step }\end{array}$ & Description & Size (s) & $\begin{array}{c}\text { Pressure } \\
\text { peaks at P4 (Pa) }\end{array}$ & $\begin{array}{c}\text { Relative } \\
\text { difference }(\xi)\end{array}$ \\
\hline 1 & Small & 0.005 & 14,350 & $1.1 \%$ \\
\hline 2 & Baseline & 0.01 & 14,195 & $3.4 \%$ \\
\hline 3 & Large & 0.02 & 13,728 & $\mathrm{p}=1.59$ \\
\hline
\end{tabular}

two mesh and time step levels considered, and $p$ is the estimated order of convergence, which are defined as Eq. (7) and Eq. (8) (Liu et al. 2016, p. 642):

$$
\begin{aligned}
& \xi=\left(f_{I}-f_{I I}\right) / f_{I I} \\
& \frac{f_{2}-f_{3}}{r_{23}^{p}-1}=r_{34}^{p}\left(\frac{f_{3}-f_{4}}{r_{34}^{p}-1}\right)
\end{aligned}
$$

where, f represents numerical solution of pressure peak at point P4; subscript I and II indicating the coarser and finer mesh compared, respectively; refinement ratio $r_{23}=n 3 / n 2$ and $r_{34}=n 4 / n 3 ; n$ represents the mesh number of elements; subscript 2 , 3 and 4 indicating the baseline, medium and high refinement mesh, respectively. In this study, the mesh refinement is performed with constant $r_{23}=r_{34}$ $=$ 1.26. Therefore, the algorithmic order of convergence can be simplified as in $\mathrm{Eq}(9)$ :

$p=\ln \left[\left(f_{2}-f_{3}\right) /\left(f_{3}-f_{4}\right)\right] / \ln (r)$

It is noticed that coarse mesh did not run properly in a solver process, and it was disregarded. The mesh dependence in terms of the relative difference, $\varepsilon$, between medium and baseline meshes equals 3.4\%. The results obtained with the high mesh show $2.4 \%$ difference from the corresponding result obtained with the medium mesh.

The value of $\mathrm{p}$ indicates that the present computational method has an order of accuracy somewhere between one and two, which is the general tendency also observed in other sloshing simulations, as in Liu et al. (2016, p. 643). All the transient results presented in this work for the tank with no baffles are obtained with the baseline mesh, reducing the computational efforts. Other meshes of transient models and steady-state models with agitation are based on the minimum element quality of baseline mesh as presented in Table 1 .

Similarly, three different time steps are adopted here, keeping the baseline mesh refinement, which are small $(0.005 \mathrm{~s})$, baseline $(0.01 \mathrm{~s})$, and large $(0.02 \mathrm{~s})$ sizes, performing with constant $\mathrm{r} 12=\mathrm{r} 23=2$. Table 2 shows a summary of the time step dependence results for transient models with no baffles tank. The

time step dependence in terms of relative difference is less than $4 \%$.

Both dependence test results provide evidence that the solutions are practically insensitive to the mesh refinement and time step size in the considered range. Time step equals $0.01 \mathrm{~s}$ was adopted for all transient models.

\subsection{Transient models - Sloshing effects}

From the numerical simulation, it is possible to identify the formation of the free surface for the volume of water inside the tank by iso-surfaces with a volume fraction value equal to 0.5 (Cavalagli et al. 2017; Močilan et al. 2017). Figures 7, 8, and 9 show the profile of the sloshing waves and other instabilities formed during the time of the imposed deceleration (as described in Fig. 3), simulating the braking operation of an agricultural sprayer with a tank without vertical baffles. It is possible to notice on the left-hand side the moment where there is the displacement of water on the tank front wall, and the right-hand side on the opposite wall for each tank level studied.

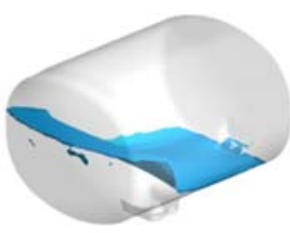

(a)

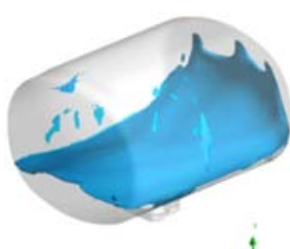

(b)

Fig. 7. Sloshing at $25 \%$ level: (a) first wave on the front wall; (b) first wave on the back wall.

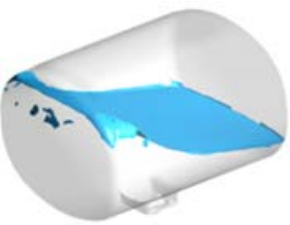

(a)

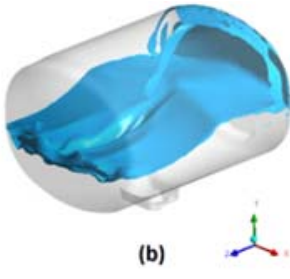

Fig. 8. Sloshing at $50 \%$ level: (a) first wave on the front wall; (b) first wave on the back wall. 


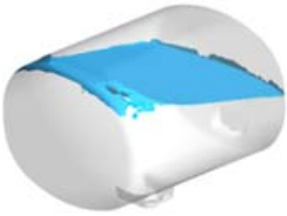

(a)

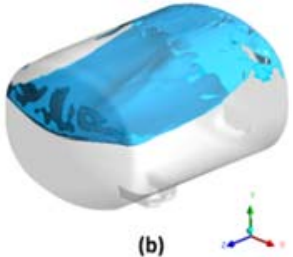

(b) dynamic pressure at these positions. In the tank fill level $75 \%$, the values are about $30 \%$ for $\mathrm{P} 1$ and $35 \%$ for P2 greater than fill level 50\%. However, for P3 and $\mathrm{P} 4$, the difference in pressure in tank fill level $50 \%$ is about $10 \%$ and $8 \%$ greater than fill level $75 \%$, respectively. The pressure peaks for all points are larger for the case of $75 \%$ fill. However, the values for the pressure difference at the points $\mathrm{P} 3$ and $\mathrm{P} 4$ are more for the case of $50 \%$. This can be interpreted as dynamic pressure due to more empty space and hence more space for fluid movement in the case of $50 \%$ fill than $75 \%$ fill.

Figure 10 shows the pressure curves on the front wall of the tank for the same simulations. The curves have a similar shape for the lower points (P3 and P4) and

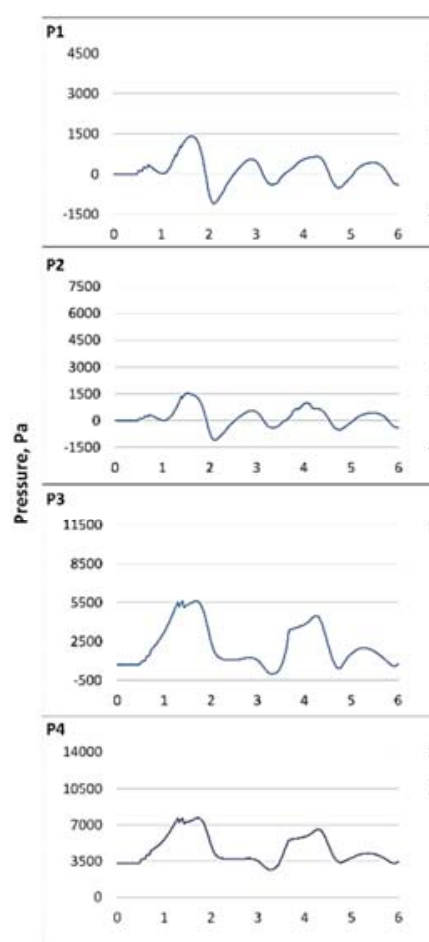

(a)

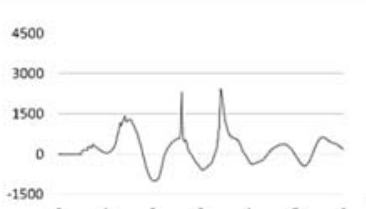

4500

3000

1500

0

1500
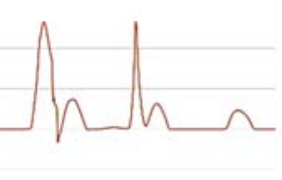

$\begin{array}{llllllllllllll}0 & 1 & 2 & 3 & 4 & 5 & 6 & 0 & 1 & 2 & 3 & 4 & 5 & 6\end{array}$

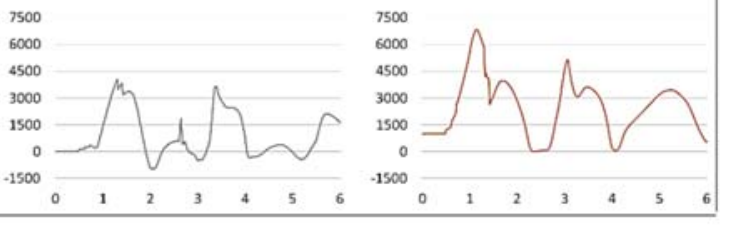

11500

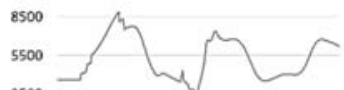

$2500-15$

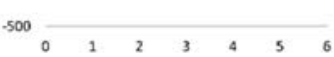

14000

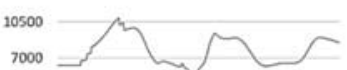

3500

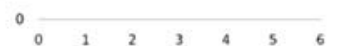

(b)
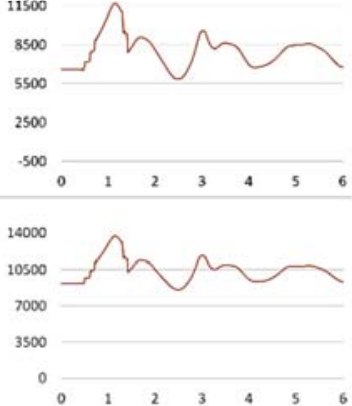

(c)

Time, s

Fig. 10. Pressure time histories on the front wall of the tank with no baffles for three different filling levels: (a) $25 \%$; (b) $50 \%$ and (c) $75 \%$.

Table 3 Pressure values for a tank without baffles

\begin{tabular}{|c|l|c|c|c|}
\hline Capture Point & \multicolumn{1}{|c|}{ Condition } & Fill Level 25\% & Fill Level 50\% & Fill Level 75\% \\
\hline \multirow{4}{*}{ P1 } & Minimum Pressure $(\mathrm{Pa})$ & -1103 & -1004 & -481 \\
\cline { 2 - 5 } & Maximum Pressure $(\mathrm{Pa})$ & 1410 & 2436 & 3986 \\
\cline { 2 - 5 } & Difference in Pressure $(\mathrm{Pa})$ & $\mathbf{2 5 1 3}$ & $\mathbf{3 4 4 0}$ & $\mathbf{4 4 6 7}$ \\
\hline \multirow{3}{*}{$\mathrm{P} 2$} & Minimum Pressure $(\mathrm{Pa})$ & -1103 & -989 & 13 \\
\cline { 2 - 5 } & Maximum Pressure $(\mathrm{Pa})$ & 1528 & 4049 & 6826 \\
\cline { 2 - 5 } & Difference in Pressure $(\mathrm{Pa})$ & $\mathbf{2 6 3 1}$ & $\mathbf{5 0 3 8}$ & $\mathbf{6 8 1 3}$ \\
\hline \multirow{3}{*}{$\mathrm{P} 3$} & Minimum Pressure $(\mathrm{Pa})$ & -34 & 2389 & 5814 \\
\cline { 2 - 5 } & Maximum Pressure $(\mathrm{Pa})$ & 5614 & 8861 & 11684 \\
\cline { 2 - 5 } & Difference in Pressure $(\mathrm{Pa})$ & $\mathbf{5 6 4 8}$ & $\mathbf{6 4 7 2}$ & $\mathbf{5 8 7 0}$ \\
\hline \multirow{3}{*}{$\mathrm{P4}$} & Minimum Pressure $(\mathrm{Pa})$ & 2652 & 5341 & 8564 \\
\cline { 2 - 5 } & Maximum Pressure (Pa) & 7673 & 10871 & 13708 \\
\cline { 2 - 5 } & Difference in Pressure (Pa) & $\mathbf{5 0 2 0}$ & $\mathbf{5 5 3 1}$ & $\mathbf{5 1 4 4}$ \\
\hline
\end{tabular}


some differences for higher points (P1 and $\mathrm{P} 2)$. This can be attributed to the fact that $\mathrm{P} 3$ and $\mathrm{P} 4$ are submerged for all levels of tank simulated, and the difference in pressure values are due to the difference of water columns below these points. On the other hand, for $\mathrm{P} 1$ and $\mathrm{P} 2$, there are additional differences due to the coincidence of the period of the pressure functions.
From the observation of pressure results, it is found that the $75 \%$ filled tank without baffles represents the critical condition to evaluate the possible effects of the arrangements proposed to alleviate the destructive effects of the sloshing problem.

Figure 11 shows the formation of the sloshing waves due to acceleration in the $z$-direction according to Fig. 3 in the case of $75 \%$ filled tank without baffles.
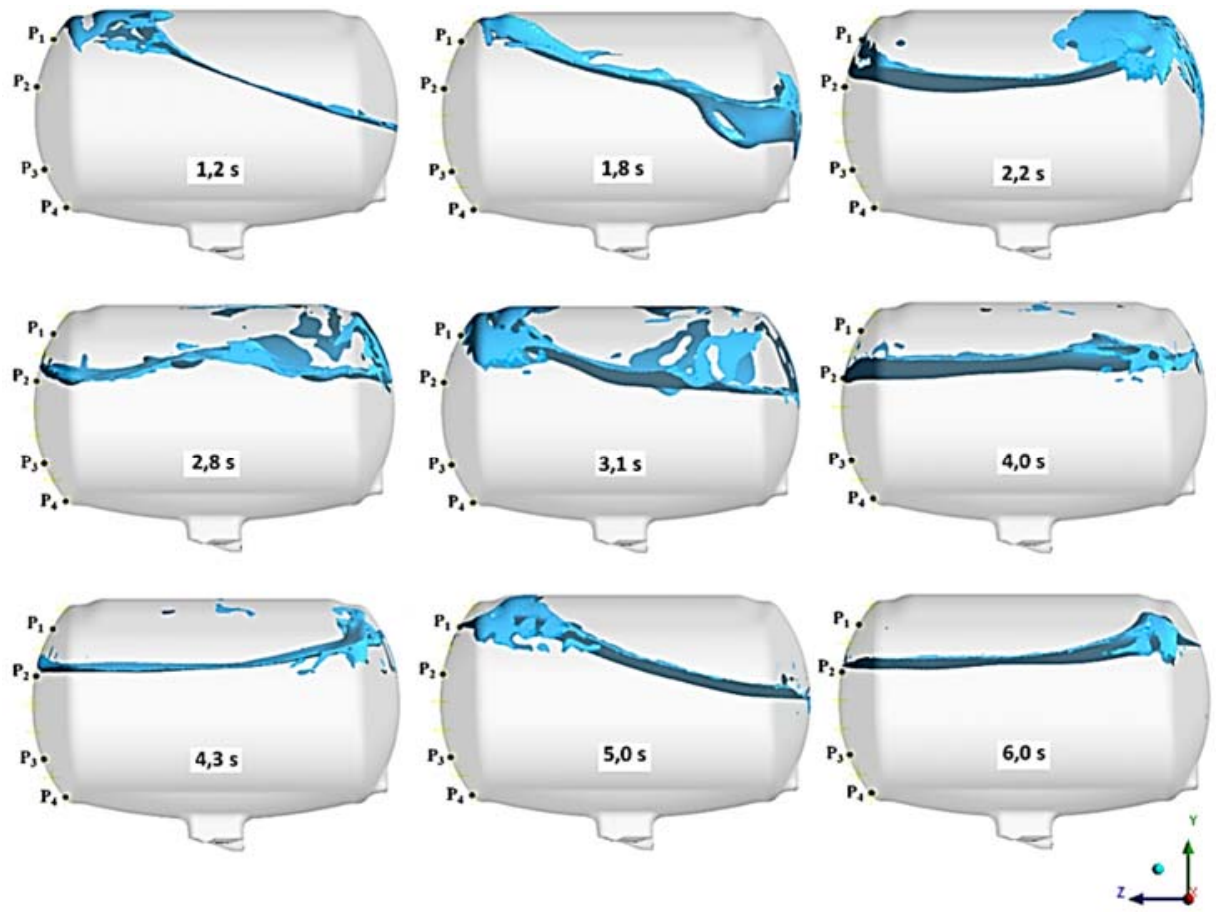

Fig. 11. 2D views of sloshing waves in the $75 \%$ filled tank without baffles.

Here, the iso-surfaces for the volume fraction of $50 \%$ represent the free surface between liquid and air inside the tank. Driven by the sloshing force, the liquid within tank moves forth and backward, correspondingly, the shape of the liquid-air interface changes, as shown at $1.2 \mathrm{~s}$ and $2.2 \mathrm{~s}$. After the first wall impact on the front and back walls, some fluctuation peaks appear in the liquid-air interface, as shown at $2.8 \mathrm{~s}$. At $3.1 \mathrm{~s}$, there is another peak of pressure on the front wall, and a second sloshing wave moves to the back wall with slightly lower energy. This is because energy is accumulated during fluid sloshing and decreasing after tank wall impacts. Some fluctuations still occur at the interface at $4.0 \mathrm{~s}$ to $6.0 \mathrm{~s}$, and the free interface tends to be stable with the consumption of sloshing energy at the end of the simulation.

Figure 12 shows a pressure distribution over the tank walls for $75 \%$ filled tank at simulation times at which pressure peaks occur, according to the indications in Fig. 10. For analysis of sloshing effects in transient models for the case of tank with no baffles, it would be possible to use a two-dimensional model due to the design of the tank (symmetry about the y-axis) and the one-dimensional deceleration (z-axis) applied in this simulation. The pressure points indicated in Fig. 2 are in the center of the tank front wall. As shown in Fig. 12, there is symmetry in the pressure gradient in the tank front views at both simulation times, and pressure changes mainly in the $y$-direction. Therefore, it is possible to notice that the pressure points chosen are adequate to represent the sloshing loads in the front tank wall.

Figure 13 shows the simulation results of the pressure distribution for arrangements 1 and 2 at the same positions on the tank front wall as indicated in Fig. 10, in comparison with the pressure distribution in the case of the tank without baffles.

Table 4 shows the simulation results of pressure capture for some points on the front wall of the tank without baffles, with arrangement 1 and arrangement 2, according indicated in Fig. 13, for fill level 75\%. It can be observed that peaks and differences of pressure of both arrangements are lower than those of the tank without baffles. Values of maximum pressure for arrangement 1 ranged about $38 \%$ for P1 and $4 \%$ for P4 lower than those of tank without baffles. Comparison of the pressure difference, this arrangement promotes a reduction of about $53 \%$ for P1 and 29\% for the other positions. For arrangement 2 , the pressure peaks decreased about $23 \%$ for $\mathrm{P} 1$ and 
G. B. Micheli et al. / JAFM, Vol. 15, No. 2, pp. 399-413, 2022.
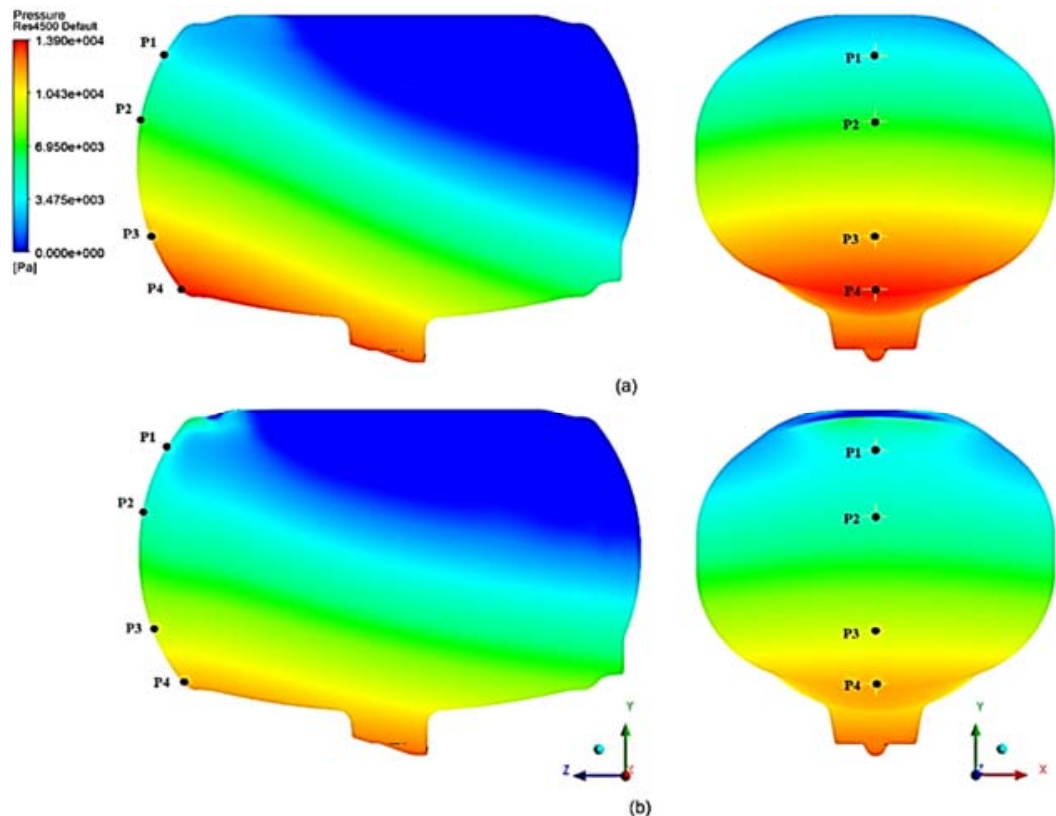

Fig. 12. Pressure profile in the tank wall (front and side views) due to acceleration in the $\mathrm{z}$-direction with: (a) simulation time $=1.2 \mathrm{~s}$; (b) simulation time $=3.1 \mathrm{~s}$.

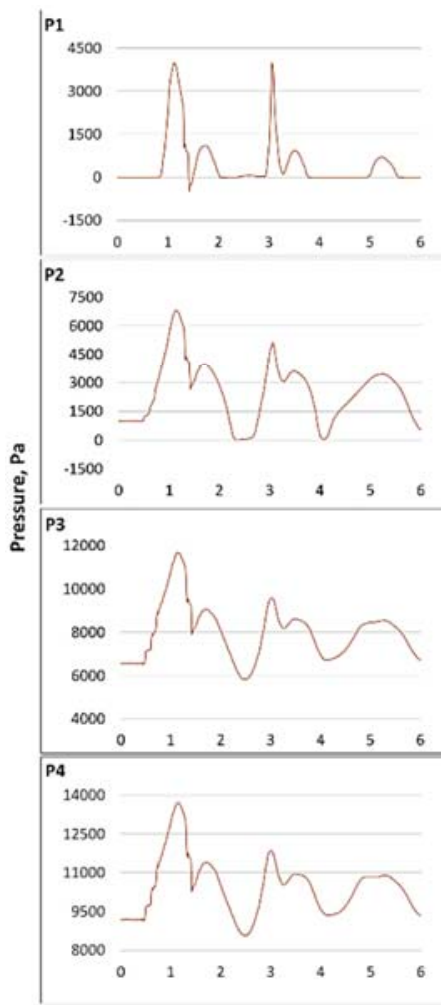

(a)
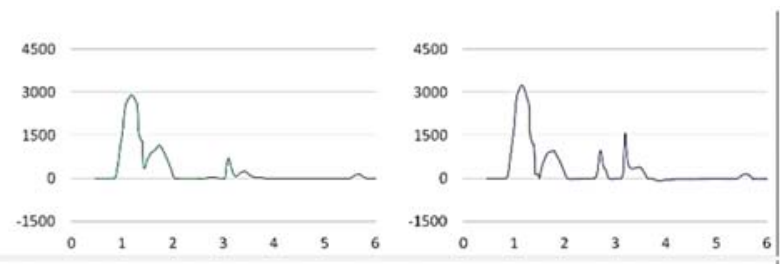

$7500 \quad 7500$
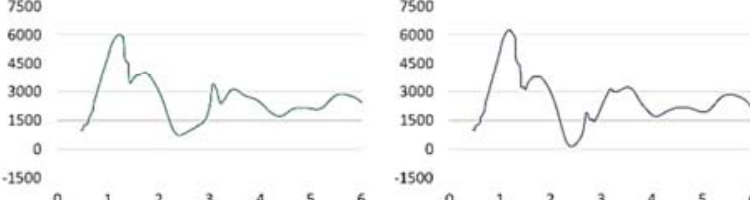

.1500
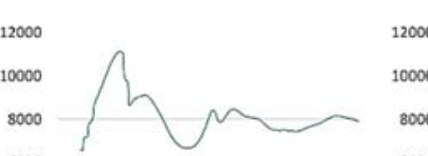

10000

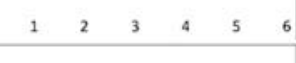

6000

8000

6000

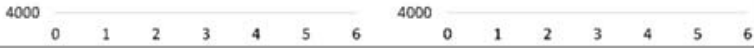

4000
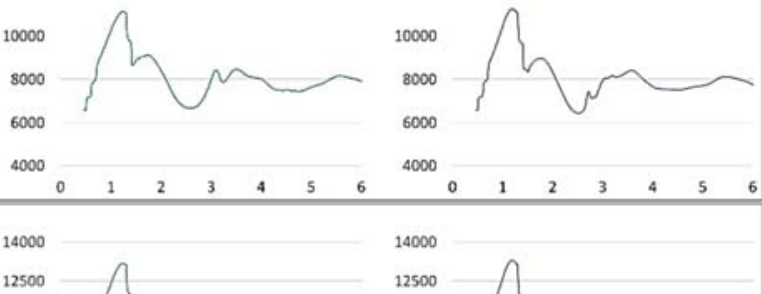

11000

9500

8000

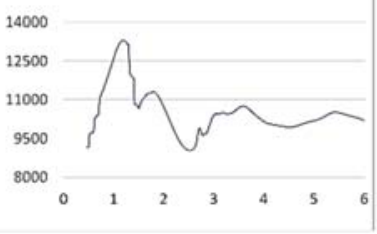

(b)

(c)

Time, 5

Fig. 13. Pressure time histories on the front wall for $75 \%$ filled tank at some conditions: (a) tank with no baffles; (b) arrangement 1; and (c) arrangement 2.

$3 \%$ for $\mathrm{P} 4$, and the pressure difference decreased $35 \%$ for $\mathrm{P} 1$ and $21 \%$ for $\mathrm{P} 4$. The results illustrate the effectiveness of the two arrangements of the baffles in suppressing the impact pressure and changing the behavior of sloshing waves. 
G. B. Micheli et al. / JAFM, Vol. 15, No. 2, pp. 399-413, 2022.

Table 4 Pressure values for proposed arrangements for Fill level 75\%

\begin{tabular}{|c|c|c|c|c|c|c|}
\hline \multirow{4}{*}{$\begin{array}{c}\begin{array}{c}\text { Capture } \\
\text { Point }\end{array} \\
\text { P1 }\end{array}$} & \multirow{2}{*}{$\begin{array}{c}\text { Condition } \\
\text { Minimum Pressure }(\mathrm{Pa})\end{array}$} & \multirow{2}{*}{$\begin{array}{c}\text { No baffles } \\
-481 \\
\end{array}$} & \multicolumn{2}{|c|}{ Arrangement 1} & \multicolumn{2}{|c|}{ Arrangement 2} \\
\hline & & & -19 & & -70 & \\
\hline & Maximum Pressure $(\mathrm{Pa})$ & 3986 & 2897 & $-38 \%$ & 3249 & $-23 \%$ \\
\hline & Difference in Pressure $(\mathrm{Pa})$ & 4467 & 2916 & $-53 \%$ & 3318 & $-35 \%$ \\
\hline \multirow{3}{*}{$\mathrm{P} 2$} & Minimum Pressure $(\mathrm{Pa})$ & 13 & 734 & & 137 & \\
\hline & Maximum Pressure $(\mathrm{Pa})$ & 6826 & 6014 & $-14 \%$ & 6247 & $-9 \%$ \\
\hline & Difference in Pressure $(\mathrm{Pa})$ & 6813 & 5280 & $-29 \%$ & 6110 & $-12 \%$ \\
\hline \multirow{3}{*}{ P3 } & Minimum Pressure $(\mathrm{Pa})$ & 5814 & 6568 & & 6436 & \\
\hline & Maximum Pressure $(\mathrm{Pa})$ & 11684 & 11117 & $-5 \%$ & 11261 & $-4 \%$ \\
\hline & Difference in Pressure $(\mathrm{Pa})$ & 5870 & 4549 & $-29 \%$ & 4826 & $-22 \%$ \\
\hline \multirow{3}{*}{ P4 } & Minimum Pressure $(\mathrm{Pa})$ & 8564 & 9152 & & 9039 & \\
\hline & Maximum Pressure $(\mathrm{Pa})$ & 13708 & 13178 & $-4 \%$ & 13299 & $-3 \%$ \\
\hline & Difference in Pressure $(\mathrm{Pa})$ & 5144 & 4026 & $-28 \%$ & 4260 & $-21 \%$ \\
\hline
\end{tabular}

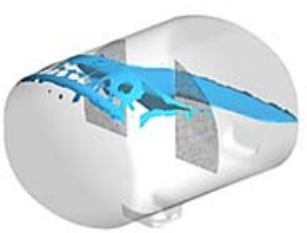

(a)

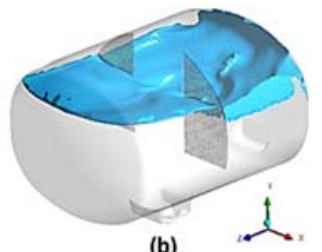

(b)
Fig. 14. Sloshing at level $75 \%$ for arrangement 1.

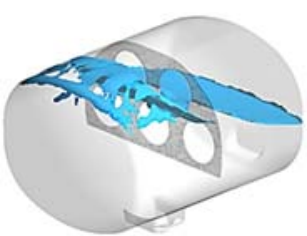

(a)

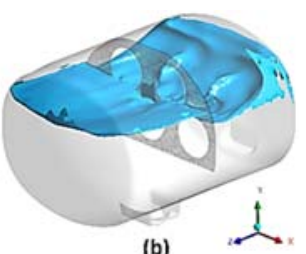

(b)
Fig. 15. Sloshing at level $75 \%$ for arrangement 2.
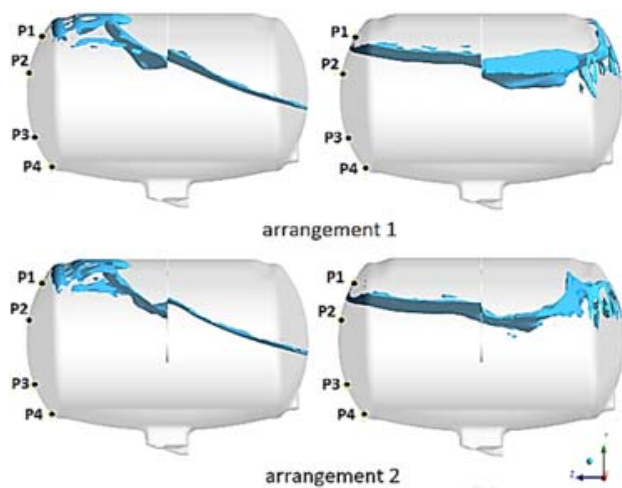

(a)

(b)

Fig. 16. 2D view of sloshing in the sprayer tank for arrangements 1 and 2 : (a) time $=1.2 \mathrm{~s}$ and (b) time $=3.1 \mathrm{~s}$.

Figures 14 and 15 show the profile of the sloshing waves formed during the deceleration period for arrangements 1 and 2, respectively. Joshi et al. (2017) analyzed the stability of a ship, modeling the generation and propagation of free surface waves in a tank having a bottom baffled arrangement which in a way like the present cases. In the present work, comparing Figs. 14 and 15 to Fig.9, one can observe the reduced formation of the hydraulic jump and roof impact in both arrangements.

Figure 16 shows the profile of the sloshing waves for tank fill level of $75 \%$ for arrangements 1 and 2 , formed during periods of occurrence of pressure peaks according to Fig. 13. Comparing the two arrangements for simulation time equal to $1.2 \mathrm{~s}$ (Fig. 16a), the heights of sloshing waves are similar. However, for simulation time equal to $3.1 \mathrm{~s}$ (Fig. 16b), the hydraulic jump formation in arrangement 2 can be observed, and sloshing elevation is lower in arrangement 1 .

Figure 17 shows pressure profiles of the tank wall for tank fill level $75 \%$ with arrangement 1 at the same simulation times indicated in Fig. 16, while Fig. 18 shows the pressure profiles for arrangement 2. As with previous models of no baffles tank, the comparison of pressure gradients shows that the pressure points indicated in Fig. 2 are adequate to predict the impact loads on the front tank wall.

Other points are added to verify the pressure distributions on the walls of the baffles, and their locations are indicated in Fig. 19. Figure 20 shows pressure gradients over the baffles for both arrangements, and Fig. 21 shows the pressure time histories for comparison. As shown in Fig. 20, there is a similar pressure gradient on the surfaces of the two arrangements. However, the first peaks of pressure for arrangement 1 are greater than those for arrangement 2 at P6, P7 and P8, as shown in Fig. 21. It can also be noticed that the values of difference in pressure for arrangement 1 are greater than those for arrangement 2 at all points. Therefore, analyzing the pressure on the baffles walls, the perforated baffle shows slightly better results than the partial vertical baffles with a central gap. The curves show a similar shape for each point for both arrangements after 4.0 s. This can be attributed to the consumption of sloshing energy.

\subsection{Steady state models - wall shear stress}

Adequate agitation of the spray mixture of herbicides in a tank is significant to ensure uniform spraying throughout the field. It is considered a project requirement in the design of tanks for agricultural 
G. B. Micheli et al. / JAFM, Vol. 15, No. 2, pp. 399-413, 2022.
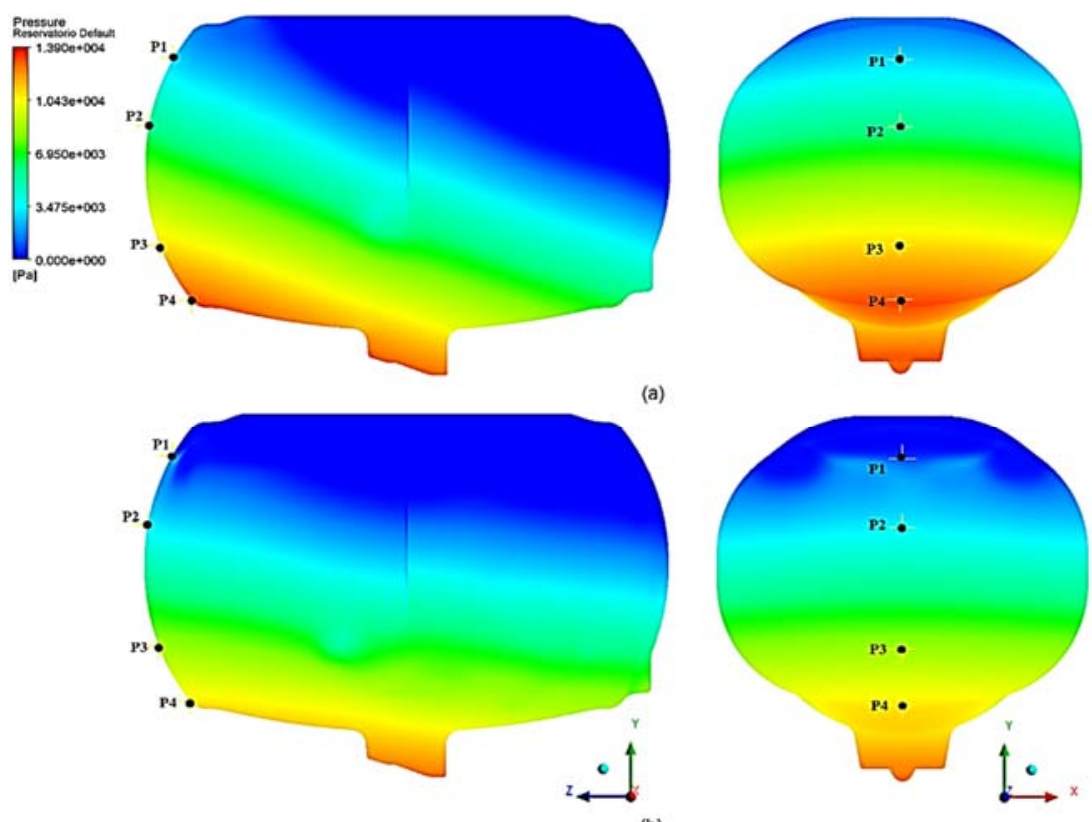

(b)

Fig. 17. Pressure profile in the tank wall (front and side views) for arrangement 1 with: (a) simulation time $=1.2 \mathrm{~s} ;(\mathrm{b})$ simulation time $=3.1 \mathrm{~s}$.
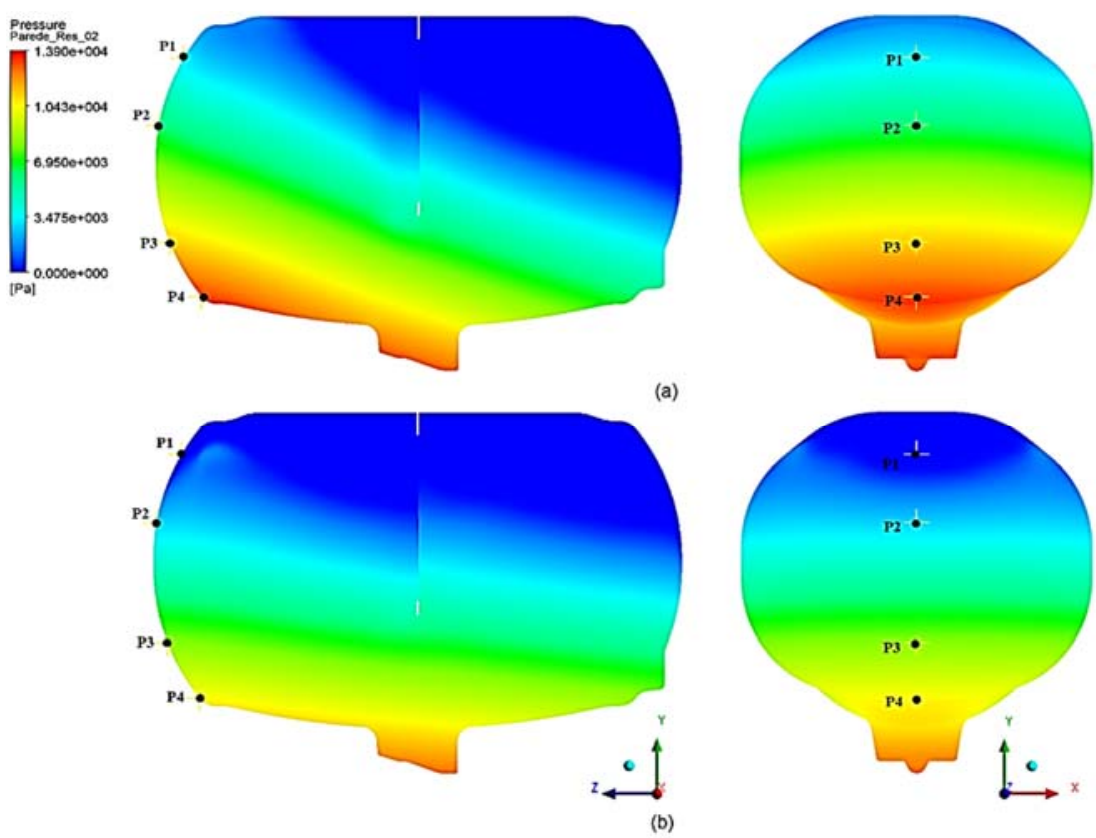

(a)

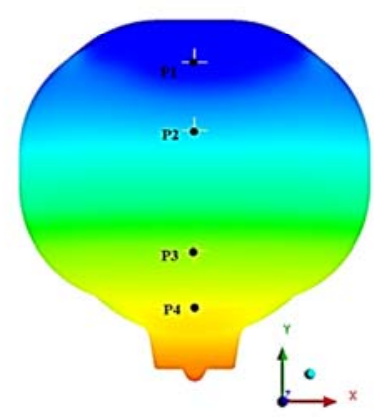

Fig. 18. Pressure profile in the tank wall (front and side views) for arrangement 2 with: (a) simulation time = 1.2s; (b) simulation time $=3.1 \mathrm{~s}$.

sprayers. El-Nahhal and Hamdona (2017) and Sousa et al. (2018) investigated the use of herbicides for weed growth control and inhibition for corn and soybean crops.

The correct application of herbicides depends on a set of factors, including the dosages used, the contamination of residues from previous applications deposited at the bottom of the spray tanks, and continuous agitation to obtain the homogeneity of the mixture.

As presented in Section 2, regions of low shear stress values are subject to a more significant occurrence of residues deposition, mainly at the bottom wall of the tank. Achieve wall shear stress levels of more than $0.3 \mathrm{~Pa}$ are required to maintain a good agitation of the tank mixture without additional mechanical agitators. 


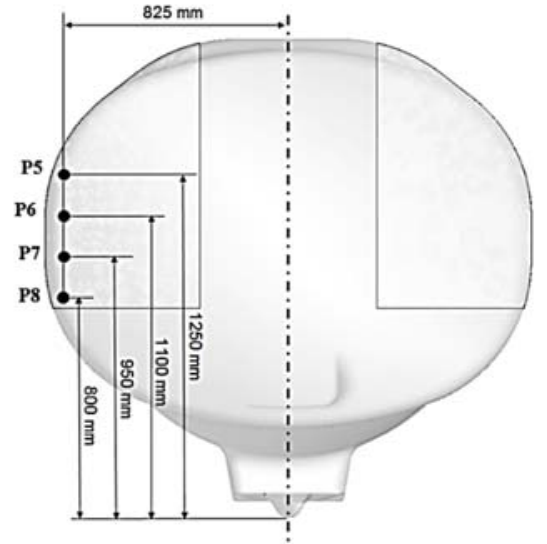

(a)

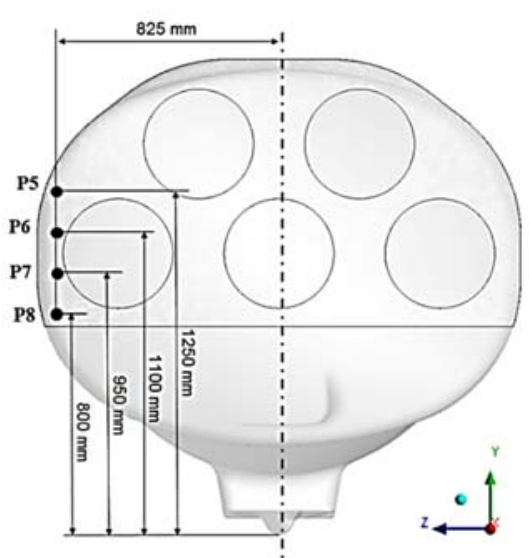

(b)

Fig. 19. Positions of pressure capture points for baffles walls: (a) arrangement 1; (b) arrangement 2.
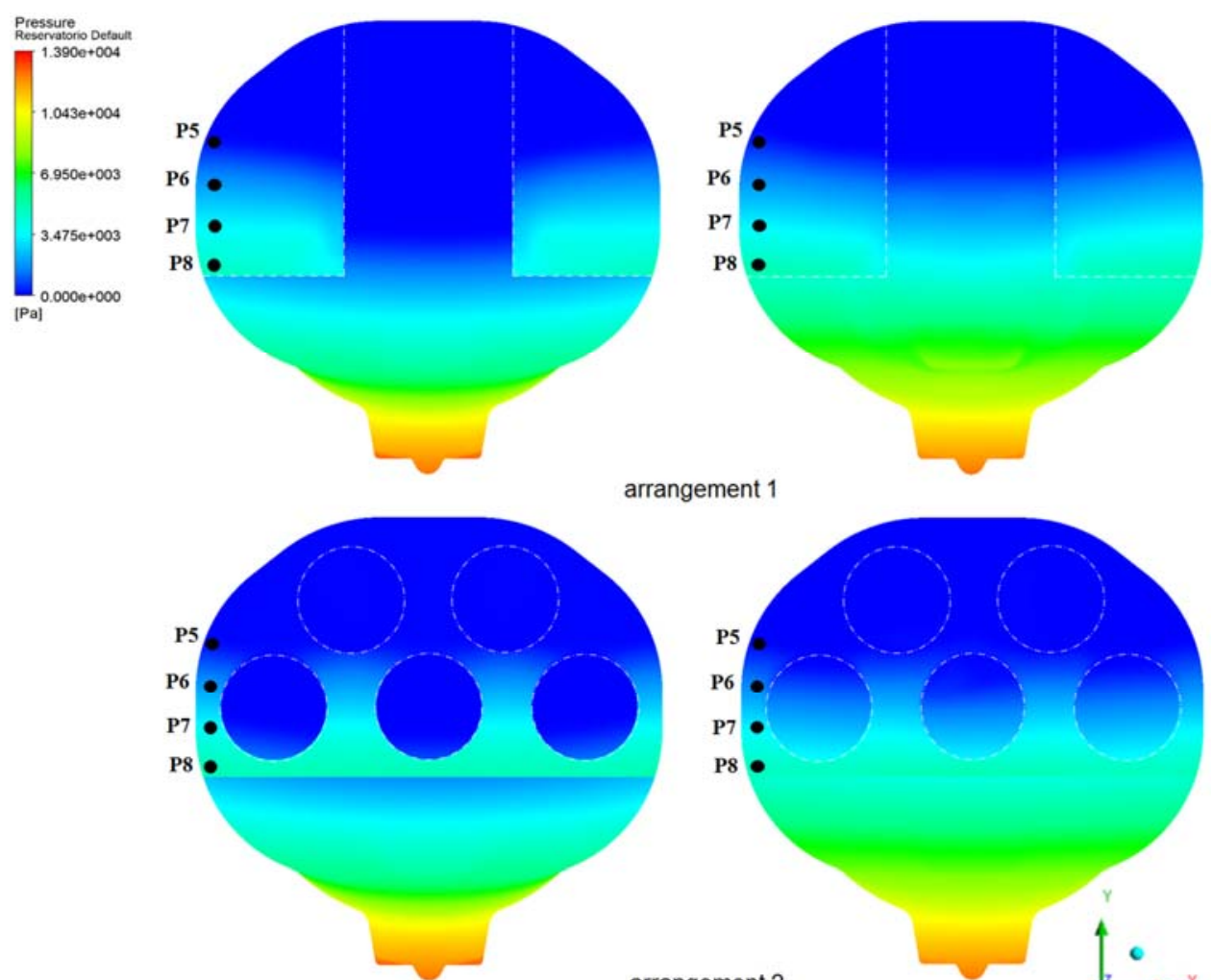

rrangement 1

(a)

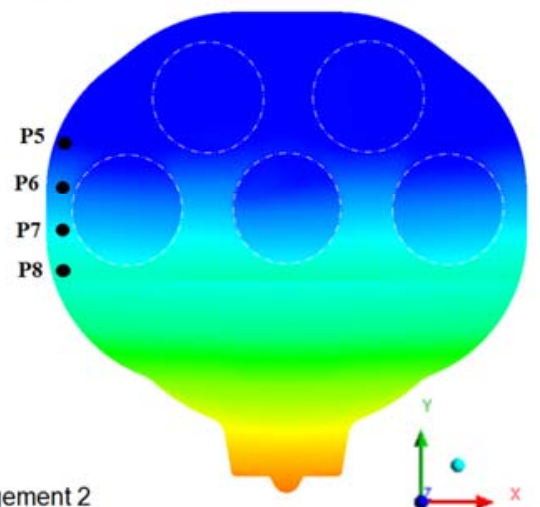

(b)

Fig. 20. Pressure profile in the baffles walls for arrangements 1 and 2 with: (a) simulation time = 1.2s;

(b) simulation time $=3.1 \mathrm{~s}$.

Before evaluating the shear stress on the tank walls, it is necessary to assess the values of the dimensionless Yplus throughout them to ensure that the results close to the wall are valid. It can be seen in Fig. 22 that the Yplus values were below the limit for the chosen turbulence model (the greater the value of the tangential flow velocity, the greater the Yplus value, for the same distance from the wall).

Having analyzed and discussed the efficiency and hydrodynamic performance aspects of the proposed arrangements to reduce sloshing effects on the tank walls, it is essential to analyze the results for the wall shear stress for the tank arrangement with no baffles and arrangements 1 and 2. Steady-state models were carried out with a fully filled tank as described in the numerical treatment section. The analysis of this variable is concentrated in the bottom wall of the tank, as it is the region with the highest probability of residue deposition. Figure 23 shows wall shear stress profiles on the tank bottom wall for all cases, with fluid motion due to the mechanical agitator. 
G. B. Micheli et al. / JAFM, Vol. 15, No. 2, pp. 399-413, 2022.

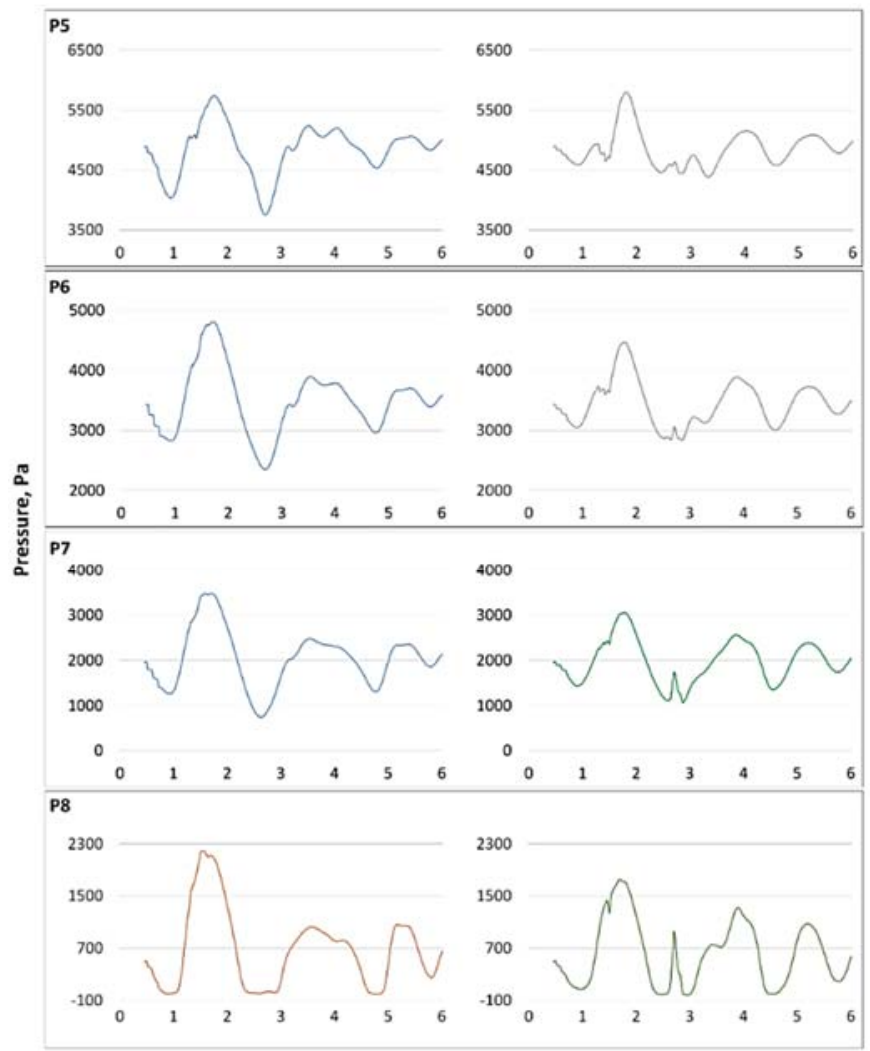

(a)

(b)

Fig. 21. Pressure time histories on the baffles walls for $75 \%$ filled tank at some conditions: (a) arrangement 1; and (b) arrangement 2.

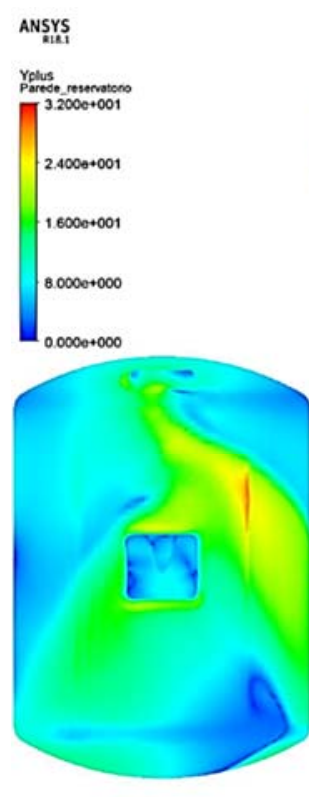

(a)
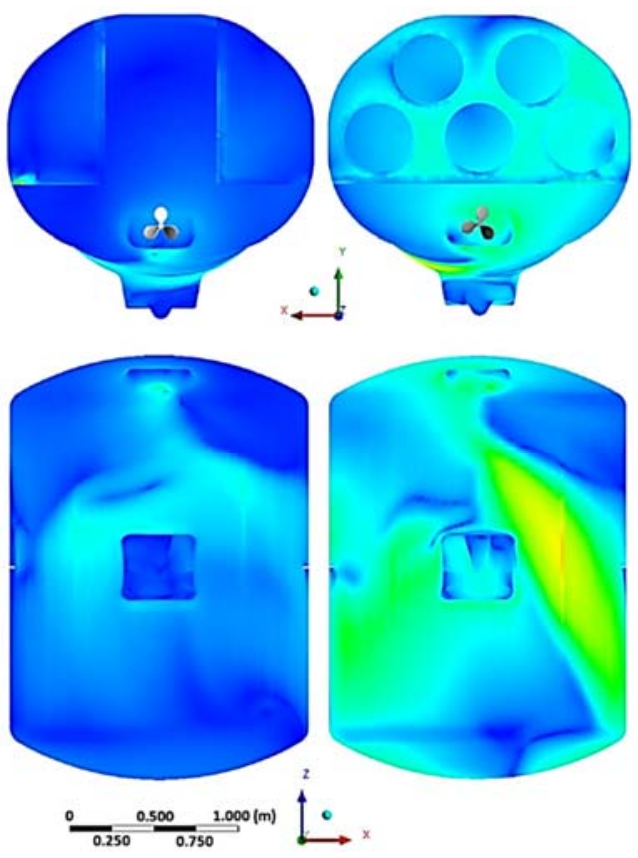

(b)

(c)

Fig. 22. Yplus values on the baffles and bottom tank walls at some conditions: (a) no baffles tank; (b) arrangement 1; and (c) arrangement 2. 


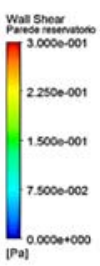

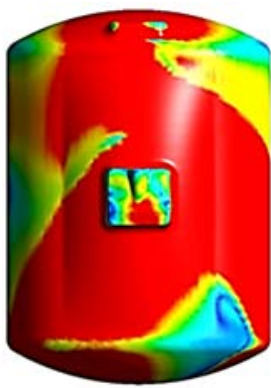

(a)

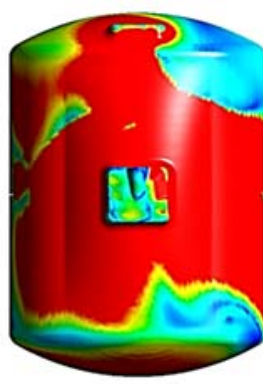

(b)

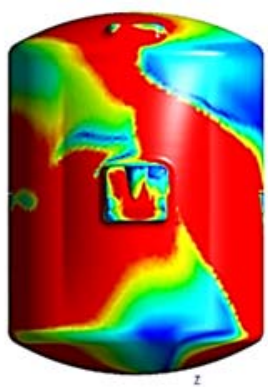

(c) $\stackrel{0}{\longrightarrow}$

Fig. 23. Wall shear stress on the tank bottom wall with: (a) no baffles tank; (b) arrangement 1; and (c) arrangement 2.

The area of the bottom tank wall where wall shear stress is lower than $0.3 \mathrm{~Pa}$ is $26 \%, 24 \%$, and $36 \%$ for the case with no baffles, arrangements 1 and 2 , respectively. It is possible to notice that arrangement 1 achieves the wall shear stress requirement at the same level as no baffles tank and could maintain the tank's original level of mechanical agitation. However, for arrangement 2, the bottom area out of the requirement increases $38 \%$ compared to no baffles tank. It shows that this proposal is not adequate as a solution for the whole problem.

\section{CONCLUSION}

In this paper, numerical models were developed for predicting the sloshing motion in a spray mixture tank. The numerical approach allowed the inclusion of the non-linear effects of sloshing formation and extract information about the stresses acting on the tank walls. The locations of the pressure points in the submerged regions and in the regions where the sloshing wave reached the highest points, helped to identify that the tank filling volume of $75 \%$ generates the highest pressure on the tank wall and produces a more significant impact on the structure of the tank. It is found that even with the minimum level of filling $(25 \%)$, there is pressure on the wall at the highest pressure point.

With the installation of baffles as in the two proposed arrangements, the sloshing instabilities were significantly reduced, along with the impact pressure values on the tank walls. A similar pressure gradient on the baffles surfaces of the two arrangements could be noticed. Arrangement 1, with two partial vertical baffles and a central gap, was the most effective arrangement, promoting a higher reduction of wall impact pressure (about $38 \%$ for pressure peak on the higher point and $29 \%$ in the pressure difference for the lower points). However, arrangement 2 achieved good results too, with a reduction of about $23 \%$ in maximum pressure at the highest pressure points and $22 \%$ in pressure difference at the lower points. These can be noticed in the behavior of sloshing waves. There is a reduced formation of the hydraulic jump and roof impact in both arrangements because energy is accumulated during fluid sloshing and decreases after the impact of the tank and baffles walls. Comparing the two arrangements for simulation time equal to $1.2 \mathrm{~s}$, the heights of sloshing waves are similar. However, for simulation time equal to $3.1 \mathrm{~s}$, the hydraulic jump formation in arrangement 2 can be observed, and sloshing elevation is lower in arrangement 1 . Some fluctuations still occur until the free interface tends to be stable with the consumption of sloshing energy at the end of the simulation.

To conclude this study, a steady-state model with mechanical agitation and fully filled tank was developed. Adequate agitation of the spray mixture of pesticides is considered a project requirement in the design of tanks for agricultural sprayers. The areas out of the agitation requirement on the lower surface of the tank are compared for both arrangements and the no baffles tank. It allowed checking if the baffles installed inside the tank hamper the original mechanical agitation. From the analysis of the results of wall shear stress of tank bottom wall, arrangement 1 was the one that maintained the same level of mechanical agitation of the tank with no baffles and at the same time reduced the undesirable sloshing effects.

\section{REFERENCES}

Ansys CFX (2017). CFX 18.1 - User's Guide, Ansys Inc.

Ansys ICEM-CFD (2017). ICEM-CFD 18.1 Theory Guide, Ansys Inc.

Bellezi, C. A., L.-Y. Cheng, T. Okada and M. Arai (2019). Optimized perforated bulkhead for sloshing mitigation and control. Ocean Engineering 187, 106171.

Cavalagli, N., C. Biscarini, A. L. Facci, F. Ubertini and S. Ubertini (2017). Experimental and numerical analysis of energy dissipation in a sloshing absorber. Journal of Fluids and Structures 68, 466-481.

Celis, M. A. C., J. B. V. Wanderley and M. A. S. Neves (2017). Numerical simulation of dam breaking and the influence of sloshing on the transfer of water between compartments. Ocean Engineering 146, 125-139.

El-Nahhal, Y. and N. Hamdona (2017). Adsorption, leaching and phytotoxicity of some herbicides as single and mixtures to some crops. Journal of the Association of Arab Universities for Basic and Applied Sciences 22, 17-25.

Fogal, M. L. F., G.B. Micheli, A. Padilha and V. L. 
G. B. Micheli et al. / JAFM, Vol. 15, No. 2, pp. 399-413, 2022.

Scalon (2021). Numerical-experimental comparison of radial fans applied in pneumatic transport of agricultural fertilizer spreaders. Revista Brasileira de Engenharia Agrícola e Ambiental 25(1), 58-64.

Gu, D., C. Cheng, Z. Liu and Y. Wang (2019). Numerical simulation of solid-liquid mixing characteristics in a stirred tank with fractal impellers. Advanced Powder Technology 30, 2126-2138

Hosain, M. L., U. Sand and R. B. Fdhila (2018). Numerical Investigation of Liquid Sloshing in Carrier Ship Fuel Tanks. IFAC-PapersOnLine 51(2), 583-588.

Iranmanesh, A. and M. Passandideh-Fard (2017). A 2D numerical study on suppressing liquid sloshing using a submerged cylinder. Ocean Engineering 138, 55-72.

Jiang, S.-C., B. Teng, W. Bai and Y. Gou (2015). Numerical simulation of coupling effect between ship motion and liquid sloshing under wave action. Ocean Engineering 108, 140-154.

Joshi, A. Y., A. Bansal and D. Rakshit (2017). Effects of baffles on sloshing impact pressure of a chamfered tank. Procedia Engineering 173, 940-947.

Kolaei, A., S. Rakheja and M. J. Richard (2014). Effects of tank cross-section on dynamic fluid slosh loads and roll stability of a partly-filled tank truck. Journal of Mechanics B/Fluids 46, 46-58.

Kolaei, A., S. Rakheja and M. J. Richard (2017). Coupled multimodal fluid-vehicle model for analysis of anti-slosh effectiveness of longitudinal baffles in a partially-filled tank vehicle. Journal of Fluids and Structures 70, 519-536.

Liu, D., W. Tang, J. Wang, H. Xue, and K. Wang (2016). Comparison of laminar model, RANS, LES and VLES for simulation of liquid sloshing. Applied Ocean Research 59, 638-649.

Liu, D., W. Tang, J. Wang, H. Xue and K. Wang (2017). Modelling of liquid sloshing using CLSVOF method and very large eddy simulation. Ocean Engineering 129, 160-176.

Liu, Z., Y. Feng, Y. Liu, G. Lei and Y. Li (2019). Hydrodynamic performance on sloshing process in a liquid oxygen tank under intermittent excitation. Cryogenics 98, 92-101.

Liu, Z., Y. Feng, Y. Liu, G. Lei and Y. Li (2020). Fluid sloshing dynamic performance in a fuel storage tank under sinusoidal excitations. Applied Thermal Engineering 168, 114814.

Lyu, W., O. el Moctar, R. Potthoff and J. Neugebauer (2017). Experimental and numerical investigation of sloshing using different free surface capturing methods. Applied Ocean Research 68, 307-324.

Micheli, G. B., A. Padilha and V. L. Scalon (2015).
Análise numérico-experimental da agitação de calda em reservatórios de pulverizadores agrícolas. Journal of the Brazilian Association of Agricultural Engineering 35(6), 1065-1078.

Močilan, M., M. Žmindák, P. Pecháč and P. Weis (2017). CFD simulation of hydraulic tank. Procedia Engineering 192, 609-614.

Myrillas, K., P. Planquart, A. Simonini, J. M. Buchlin and M. Schyns (2017). CFD and experimental investigation of sloshing parameters for the safety assessment of HLM reactors. Nuclear Engineering and Design 312, $317-326$

Nicolsen, B., L. Wang and A. Shabana (2017). Nonlinear finite element analysis of liquid sloshing in complex vehicle motion scenarios. Journal of Sound and Vibration 405, 208-233.

Park, W. M., D. K. Choi, K. Kim, S. M. Son, S. H. Oh, K. H. Lee, H. S. Kang and C. Choi (2019). (2019). Simple analytical method for predicting the sloshing motion in a rectangular pool. Nuclear Engineering and Technology 52, 947955.

Pukkella, A. K., R. Vysyaraju, V. Tammishetti, B. Rai and S. Subramanian (2019). Improved mixing of solid suspensions in stirred tanks with interface baffles: CFD simulation and experimental validation. Chemical Engineering Journal 358, 621-633.

Qin, H., L. Mu, W. Tang and Z. Hu (2019). Numerical study on structural response of antisloshing baffles of different configurations in a sloshing tank considering hydroelasticity. Ocean Engineering 188, 106290.

Saghi, H. and E. Lakzian (2017). Optimization of the rectangular storage tanks for the sloshing phenomena based on the entropy generation minimization. Energy 128, 564-574.

Sousa, J. B., M. B. Teixeira, A. Jakelaitis, F. N. Cunha and N.F. Silva (2018). Performance of Crops Grown in Succession to Soybeans Treated with Different Residual Herbicides. Planta Daninha 36 (e018160229).

Sufyan, M., L. C. Ngo and H. G. Choi (2017). A dynamic adaptation method based on unstructured mesh for solving sloshing problems. Ocean Engineering 129, 203-216.

Wang, W., Y. Peng, Q. Zhang, L. Ren and Y. Jiang (2017). Sloshing of liquid in partially liquid filled toroidal tank with various baffles under lateral excitation. Ocean Engineering 146, 434 456.

Xue, M. A., J. Zheng, P. Lin and X. Yuan (2017). Experimental study on vertical baffles of different configurations in suppressing sloshing pressure. China Ocean Engineering 136, 178 189.

Zhang, C., P. Su and D. Ning (2019). Hydrodynamic study of an anti-sloshing technique using floating foams. Ocean Engineering 175, 62-70 